\title{
Changes in Antioxidant Activity and Organoleptic Quality of Mixed Fruit Leather during Drying and Storage
}

Biến đổi hàm lượng chất chống oxi hoá và chất lượng cảm quan của bánh tráng trái cây hỗn hợp trong quá trình sấy và bảo quản

\author{
Hoang Quang Binh ${ }^{1,2}$, Do Thi Thuy Lien ${ }^{1}$, Le Trung Thien ${ }^{1,2 *}$ \\ ${ }^{1}$ Faculty of Food Science and Technology, Nong Lam University, Ho Chi Minh City, Vietnam \\ ${ }^{2}$ Fresh Soul Nong Lam Co., Ltd \\ *Email: le.trungthien@hcmuaf.edu.vn
}

\begin{abstract}
Fruit leather is a dried fruit product made from one or more different fruits and food additives. It not only gets good taste but also contains many valuable antioxidant compounds such as polyphenols, vitamin C. However, these compounds easily are deteriorated under temperature, oxygen, and light during processing and storage. This study evaluated the effect of drying temperature $\left(50 ; 60,70^{\circ} \mathrm{C}\right.$, and drying time $(9-18$ hours) on the change of antioxidant compounds as well as the organoleptic quality of fruit leather mix (gac fruit, papaya, aloe vera, passion fruit seeds). Besides, the retention of antioxidant compounds and color of the product under the different packaging such as polyamide (PA) and aluminum-coated polypropylenen (PP) bags during storage evaluated. The results showed that the sample was dried at $60^{\circ} \mathrm{C}$ for 15 hours gave the polyphenol content of $321.67 \mathrm{mg} \mathrm{GAE} \mathrm{/} 100 \mathrm{~g} \mathrm{dm}$, the vitamin C content of $49.30 \mathrm{mg} \mathrm{AAE} \mathrm{/} 100 \mathrm{~g} \mathrm{dm}$ and water activity of 0.54 , moisture content of $17.17 \%$. After storing at room temperature for 2 months, the samples were packed in $P A$ and PP had polyphenol retention of $87.23 \%$ and $84.42 \%$, respectively; vitamin C retention of $78.96 \%$ and $83.67 \%$ respectively, $\Delta E$ value of 3.41 and 2.07 , respectively. Further studies should be carried out to finding a way to improve stability for polyphenol and vitamin $C$ of the sample.
\end{abstract}

Keywords: Antioxidant compound, color, fruit leather, processing, storage

Tóm tắt

Bánh tráng trái cây là sản phẩm trái cây sấy được làm từ một hoặc nhiều loại trái cây khác nhau phối trộn cùng với các chất phụ gia. Bên cạnh hương vị đặc trưng, sản phẩm còn chứa nhiều các hợp chất chống oxy hóa quý giá như polyphenol, vitamin C. Đây là các hợp chất dễ bị biến đổi dưới tác động của nhiệt độ, oxy, ánh sáng trong quá trình chế biến cũng như bảo quản. Nghiên cứu này đã lần lượt đánh giá ảnh hưởng của nhiệt độ sấy (50; 60 và $70^{\circ} \mathrm{C}$ thời gian sấy (9-18 giờ) đến sự biến đổi hợp chất chống oxy hóa và chất lượng cảm quan của sản phẩm bánh tráng trái cây hỗn hợp (gấc, đu đủ, nha đam, hạt chanh dây). Bên cạnh đó, khả năng duy trì các hợp chất chống oxy hóa và màu sắc của sản phẩm dưới tác động của loại bao bì $P A$ và bao PP tráng nhôm trong quá trình bảo quản cũng được ghi nhận. Kết quả nghiên cứu cho thấy sản phẩm được sấy tại $60^{\circ} \mathrm{C}$ trong thời gian 15 giờ cho hàm lượng polyphenol là 321,67 mg GAE /100g vck, hàm lượng vitamin C là 49,30 mg AAE/100g và hoạt độ nước 0,54, hàm lượng ẩm 17,17\%, cũng như chất lượng cảm quan tốt. Sau 2 tháng bảo quản tại nhiệt độ phòng, mẫu được đóng gói trong bao PA và bao PP tráng nhôm lần lượt có hàm lượng polyphenol còn lại là $87,23 \%$ và $84,42 \%$; hàm lượng vitamin $C$ còn lại là $78,96 \%$ và 83,67, giá trị $\Delta E$ là 3,41 và 2,07. Cần tiếp tục có các thí nghiệm nghiên cứu cải thiện khả năng ổn định polyphenol, vitamin $C$ và màu sắc của sản phẩm.

Từ khóa: Bánh tráng trái cây, bảo quản, chống oxy hóa, chế biến, màu sắc

\section{1. Đặt vấn đề}

Trái cây từ lâu đã được biết là nguồn cung cấp quan trọng nhiều hợp chất có lợi cho sức khỏe. Tuy nhiên, loại nông sản này lại có hạn sử dụng ngắn. Theo báo cáo của Ghamrawy khoảng $45 \%$ lượng rau quả bị loại bỏ do hư hỏng [1]. Việt Nam có nguồn trái cây nhiệt đới đa dạng với số lượng lớn như đu đủ, chanh dây, gấc. Tuy nhiên các loại trái cây này chủ yếu được sử dụng ăn tươi, còn ít các sản phẩm chế biến sâu. Các sản phẩm mới từ trái cây giúp đa dạng hóa sản phẩm và gia tăng giá trị kinh tế cho các loại nông sản này

Sấy là phương pháp chế biến, bảo quản thực phẩm phổ biển; giúp loại nước ra khỏi thực phẩm, từ đó làm giảm hoạt độ nước của thực phẩm đến vùng bảo quản an toàn [2]. Sấy đối lưu (không khí nóng) có đặc điểm chi phí đầu tư thấp, thời gian sử dụng lâu, dễ vận hành [2]. Phương pháp này thường được sử dụng chế biến trái cây sấy khô, đặc biệt phù hợp cho các doanh

ISSN: 2734-9381

https://doi.org/10.51316/jst.153.etsd.2021.31.4.2

Received: December 11, 2020; accepted: October 01, 2021 
nghiệp chế biến quy mô vừa và nhỏ áp dụng. Trái cây sấy dạng miếng được chế biến chủ yểu từ trái cây có hoặc không bồ sung thêm các chất tạo cấu trúc, chất điều vị; do đó sản phẩm được xem là nguồn cung chất nhiều hợp chất có lợi cho sức khỏe như: các chất chống oxy hóa, vitamin $\mathrm{C}$, chất khoáng, chất xơ $[3,4]$. Sản phẩm này có thể xem như là món ăn vặt có lợi cho sức khỏe thay thế cho các món ăn vặt giàu chất béo khác.

Hiện trong nước các nghiên cứu có liên quan về bánh tráng trái cây còn chưa nhiều. Trong nhiều nghiên cứu trước đó về bánh tráng trái mơ [5], bánh tráng táo [6], bánh tráng lựu [7], các tác giả đã cho thấy các hợp chất chống oxy hóa như polyphenol và vitamin $\mathrm{C}$ rất dễ bị tổn thất dưới tác động của nhiệt độ sấy trong quá trình chế biến. Ngoài ra, trong một báo cáo tổng hợp của Diamante về bảo quản sản phẩm bánh tráng trái cây, cũng đã cho thấy vật liệu bao gói là một trong những yểu tố chính tác động đến sự biến đổi của các hợp chất chống oxy hóa này [3]. Do đó mục đích của nghiên cứu này, nhằm đánh giá ảnh hưởng của nhiệt độ và thời gian sấy đến sự biến đổi của các hợp chất này có trong sản phẩm trái cây sấy hỗn hợp. Đồng thời sự biến đổi của các hợp chất này dưới ảnh hưởng của loại vật liệu bao gói trong quá trình bảo quản cũng được ghi nhận.

\section{Phương pháp nghiên cứu}

\subsection{Nguyên liệu hóa chất và thiết bị}

$Đ u$ đủ (Carica papaya L.) được sử dụng trong nghiên cứu được trồng tại tỉnh Long An, có đặc điểm $60 \%$ bề mặt vỏ quả chuyển màu vàng, trơn láng, không bị hư hỏng. Trái có khối lượng khoảng $800-1000 \mathrm{~g}$. Đu đủ được rửa sạch, gọt vỏ, loại bỏ hạt, cắt thành các khoanh có bề rộng $3 \mathrm{~cm}$. Nguyên liệu tiếp theo được đem đi chần ở nhiệt độ $85^{\circ} \mathrm{C}$ trong 2 phút . Nguyên liệu sau sơ chế được bảo quản ở nhiệt độ $-18^{\circ} \mathrm{C}$ cho đến khi sử dụng.

Chanh dây vo tím (Passiflora foetida $\mathrm{L}$.) được thu mua có đặc điểm bề mặt vỏ quả trơn bóng, ít nhăn nheo, không có dấu hiệu hư hỏng, khối lượng quả $72-80$ g. Nguyên liệu được trồng tại Bảo Lộc, Lâm Đồng. Quả chanh dây được rửa sạch và sử dụng dao cắt đôi quả. Hỗn hợp gồm dịch quả và hạt chanh dây được lọc qua rây có lỗ lọc $1 \mathrm{~mm}$, để tách riêng từng nguyên liệu. Sau đó mỗi nguyên liệu được bảo quản riêng biệt ở nhiệt độ $-18{ }^{\circ} \mathrm{C}$ cho đến khi sử dụng, quá trình cấp đông chậm giúp hạt chanh dây giòn xốp sau khi rang. Chuẩn bị hạt chanh dây: hạt được rã đông và chà rửa dưới vòi nước để loại bỏ bớt phần màng hạt. Tiếp theo, hạt được sấy ở nhiệt độ $60^{\circ} \mathrm{C}$ đến độ ẩm khoảng $6 \%$ (thời gian sấy $5-6$ tiếng). Kế tiếp, mẫu được sàng loại bỏ phần màng hạt còn sót lại và đem rang với muối ở nhiệt độ $140{ }^{\circ} \mathrm{C}$ trong 5 phút. Sau khi nguội, hạt chanh dây được xay thành hạt nhỏ bằng máy xay sinh tố ở mức số 3 trong 5 phút.

Nha đam (Aloe vera $\mathrm{L}$.) được gọt vỏ, rửa sạch và sử dụng trực tiếp khi chế biến, không qua cấp đông.
Mỗi lá nha đam dài khoảng $30 \mathrm{~cm}$, khối lượng khoảng $0,5 \mathrm{~kg}$.

Tất cả các nguyên liệu đu đủ, chanh dây và nha đam được thu mua từ chợ đầu mối nông sản thực phẩm Thủ Đức, TP. HCM.

Puree gấc (Momordica cochinchinensis Spreng): được cung cấp bởi Công ty TNHH Lê Trung Thiên số 450, Nguyễn Xiển, TP Thủ Đức, TP. Hồ Chí Minh. Puree được đựng trong bao polyamide (PA) có trọng lượng $1 \mathrm{~kg}$, bảo quản nhiệt độ $-18^{\circ} \mathrm{C}$. Puree gấc có màu đỏ cam. Puree gấc có độ Brix là $10,6 \%$; $\mathrm{pH} 5,9$; axit tổng số là $0,12 \%$.

Hóa chất: Ascorbic acid 99,5\%, gallic acid 99\%, 2,4-DNPH, sodium bicarbonate 99,8\%, metaphosphoric acid, acetic acid, thioure, brom 33\%, $\mathrm{H}_{2} \mathrm{SO}_{4}$ 98\% (Xilong, Trung Quốc); Folin-Ciocalteu 99,5\% (Merck, Đức), Ethanol 99,6\% (Chemsol, Việt Nam),

Thiết bị: cân phân tích $10^{-4} \mathrm{PA} 214$ Ohaus (Mỹ), tủ sấy khí nóng National C - 30N (Nhật Bản), máy đo màu Konica Minolta Chroma Meter CR - 400 (Nhật Bản), máy đo quang phổ UV Vis V730 Jasco (Nhật Bản), máy đo độ Brix cầm tay $0-100^{\circ} \mathrm{Bx}$ (Atago, Nhật Bản), máy xay (Philips HR2118, 600W, Hà Lan), máy rang (N21 Barell, Trung Quốc)

\subsection{Quy trình chuẩn bị mẫu}

Tất cả các nguyên liệu sau khi rã đông được phối trộn theo tỷ lệ gồm 5,74\% puree gấc, 51,62\% đu đủ, $14,70 \%$ nha đam, $1,47 \%$ hạt chanh dây, $14,71 \%$ nước chanh dây, $11,39 \%$ saccharose, $0,15 \%$ pectin HMP, $0,22 \%$ xanthan gum. Hỗn hợp nguyên liệu được xay bằng máy xay sinh tố trong 2 phút, sau đó hồn hợp được gia nhiệt ở $85{ }^{\circ} \mathrm{C}$ khoảng 15 phút. Năm mươi gram mẫu được rót vào khuôn giấy nến có kích thước $7 \times 7 \mathrm{~cm}$ và độ dày $3 \mathrm{~mm}$. Mẫu được sấy ở nhiệt độ $60^{\circ} \mathrm{C}$ tốc độ gió $0,24 \mathrm{~m} / \mathrm{s}$ cho đến khi độ ẩm đạt khoảng $16 \% \pm 1$. Mẫu sau sấy được để nguội và bảo quản trong các bao bì polyamide ở nhiệt độ phòng $29-31{ }^{\circ} \mathrm{C}$.

\subsection{Bố trí thí nghiệm}

\subsubsection{Anh hương của nhiệt độ sấy đến chất lượng sản phẩm}

Thí nghiệm được bố trí một yếu tố là nhiệt độ sấy được thay đổi ở $50^{\circ} \mathrm{C} ; 60^{\circ} \mathrm{C}$ và $70^{\circ} \mathrm{C}$. Quy trình chuẩn bị mẫu được thực hiện tương tự mục 2.2 . Mẫu sau sấy được để nguội và bảo quản trong các bao bì polyamide ở nhiệt độ phòng $29-31^{\circ} \mathrm{C}$. Mẫu thí nghiệm được phân tích hàm lượng polyphenol tổng số, hàm lượng vitamin $C, L^{*} a^{*} b^{*}$ và mức độ yêu thích của cảm quan viên.

\subsection{2. Ảnh huởng thời gian sấy đến chất luợng sản phẩm}

Thí nghiệm được bố trí một yếu tố là thời gian sấy được thay đổi trong khoảng 9 - 18 giờ; với sự khác 
biệt giữa các nghiệm thức là 1,5 giờ. Quy trình chuẩn bị mẫu được thực hiện tương tự mục 2.2 ; trong đó nhiệt độ sấy là kết quả thí nghiệm mục 2.3.1. Mẫu sau sấy được để nguội và bảo quản trong các bao bì polyamide ở nhiệt độ phòng $29-31{ }^{\circ} \mathrm{C}$. Mẫu thí nghiệm được phân tích ẩm độ, hoạt độ nước, hàm lượng polyphenol tổng số, hàm lượng vitamin $C, L^{*} a * b^{*}$ và mức độ yêu thích của cảm quan viên.

\subsubsection{Anh hưởng của loại bao bì bao gói đến chất luợng sản phẩm trong quá trình bảo quản}

Thí nghiệm được bố trí một yếu tố là loại bao bì bao gói gồm bao polyamide (bao PA) có kích thước $7 \mathrm{x} 12 \mathrm{~cm}$, độ dày 1 lớp bao là $0,10 \mathrm{~mm}$ và polypropylen một mặt tráng nhôm (PP tráng nhôm) có kích thước $7 \times 12 \mathrm{~cm}$, độ dày 1 lớp bao là $0,16 \mathrm{~mm}$. Quy trình chuẩn bị mẫu được thực hiện tương tự mục 2.3.2; thời gian sấy là kết quả thí nghiệm mục 2.3.2. Mẫu sau sấy được để nguội và bảo quản trong các bao bì polyamide ở nhiệt độ phòng $29-31^{\circ} \mathrm{C}$. Sau các thời gian bảo quản $0,10,30,45,60$ ngày mẫu thí nghiệm được phân tích hàm lượng polyphenol tổng số, hàm lượng vitamin $C, L^{*} a^{*} b^{*}$.

\subsection{Các phương pháp phân tích}

Hàm lương polyphenol tổng (TPC): Hàm lượng polyphenol tổng của mẫu được xác định theo phương pháp Folin - Ciocalteu [8].

Hàm lương vitamin $C$ : Hàm lượng vitamin $C$ của mẫu được xác định theo phương pháp đo quang phổ UV-VIS [9].

Phân tích chi số $L^{*}, a^{*}, b^{*}$ : sử dụng máy đo màu Konica Minotal, với $L^{*}$ thể hiện độ sáng chạy từ $0-100$; giá trị $a^{*}$ thể hiện sắc đỏ, giá trị $a^{*}$ âm thể thiện sắc xanh lá; giá trị $b^{*}$ dương thể hiện sắc vàng, giá trị $b^{*}$ âm thể hiện sắc xanh dương. $\Delta \mathrm{E}=\sqrt{\left(L_{0}-L_{1}\right)^{2}+\left(a_{0}-a_{1}\right)^{2}+\left(\left(b_{0}-b_{1}\right)^{2}\right.}$ trong đó $L_{0}, a_{0}, b_{0}$ lần lượt là giá trị của mẫu trước bảo quản, $L_{l}$, $a_{1}, b_{1}$ lần lượt là giá trị của mẫu sau bảo quản [10].

Phuong pháp cảm quan mẫu được cảm quan bằng phép thử cho điểm thị hiếu theo thang điểm 7 ; trong đó 1 : cực kì không thích và 7 : cực kì thích [11] Mẫu thí nghiệm được đánh giả bởi 20 cảm quan viên sinh viên. Các cảm quan viên không sử dụng bất kì thực phẩm nào trước 30 phút thử mẫu. Mỗi cảm quan viên được nhận $10 \mathrm{~g}$ mẫu, mẫu đựng trong đĩa trắng, mỗi mẫu được mã hóa bằng số 3 chữ số. Sau mỗi lần thử mẫu, người đánh giá sử dụng nước lọc để thanh vị.

Âm độ được xác định bằng máy sấy ẩm hồng ngoại cân ẩm hồng ngoại MX - 50 - AND (Nhật Bản). Hoạt độ nước được xác định bằng máy AquaLab (DECAGON - Mỹ) tại nhiệt độ $25^{\circ} \mathrm{C}$.

\subsection{Xủ lý số liệu}

Tất cả các thí nghiệm được lặp lại 3 lần, các kết quả được thể hiện dưới dạng trung bình \pm độ lệch chuẩn. Các số liệu thu thập được tính toán, vẽ đồ thị bằng Excel 2013.Các phân tích phương sai (Anova) được thực hiện, sự khác biệt về mặt thống kê của các kết quả được xử lý bằng phần mềm JMP 13.0 tại $p<0,05$.

\section{Kết quả nghiên cứu}

\subsection{Anh hưởng của nhiệt độ sấy đến chất luọng sản phẩm}

Sự giảm ẩm của mẫu trong quá trình sấy tỷ lệ thuận với mức tăng nhiệt độ sấy (Hình 1). Sản phẩm đạt độ ẩm $16 \% \pm 1$ thì thời gian sấy cần thiết là 10 giờ ở $70{ }^{\circ} \mathrm{C}, 14$ giờ ở $60^{\circ} \mathrm{C}$ và 16 giờ ở $50^{\circ} \mathrm{C}$. Nhiệt độ càng cao, lượng nhiệt năng cung cấp cho nước di chuyển từ bên trong ra bề mặt mẫu càng lớn; nước bay hơi nhanh, điều này giúp rút ngắn thời gian sấy. Tốc độ thoát ẩm ở cùng 1 chế độ sấy có sự khác nhau đáng kể ở các giai đoạn khác nhau của quá trình sấy. Tại nhiệt độ $60^{\circ} \mathrm{C}$, trong 8 tiếng đầu của quá trình sấy mầu đã giảm 43,18\% ẩm; trong khi đó; từ 8 giờ đến 16 giờ mẫu chỉ giảm $18,34 \%$. Ở giai đoạn đầu của quá trình sấy, lượng nước bốc hơi chủ yếu là nước tự do ở lớp ngoài của sản phẩm, vì vậy tốc độ giảm ẩm của sản phẩm nhanh hơn. Khi mẫu đạt độ ẩm tới hạn, bề mặt của sản phẩm khô, mạng lưới liên kết các phân tử mạnh hơn, tốc độ thoát hơi nước chậm lại, nước trong sản phẩm lúc này ở dạng liên kết.

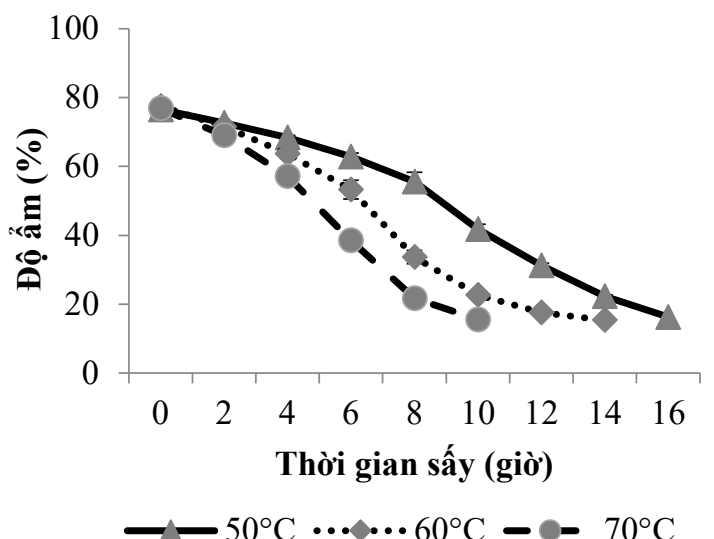

Hình 1. Ảnh hưởng của nhiệt độ sấy đến độ ẩm của bánh tráng theo thời gian sấy

Hàm lượng vitamin $\mathrm{C}$ của mẫu ở cả ba nhiệt độ sấy tương ứng lần lượt là $47,06 \mathrm{mg} / 100 \mathrm{~g}$ vật chất khô (vck), 49,30 mg/100g vck và 46,65 (mg/100g vck). Hàm lượng polyphenol tổng cao nhất là ở $60{ }^{\circ} \mathrm{C}$ (312,58 (mg/100g vck) khác biệt có ý nghĩa thống kê $(p<0.05)$ so với giá trị ở $70{ }^{\circ} \mathrm{C}$ là $279,08(\mathrm{mg} / 100 \mathrm{~g}$ vck $)$ và $236,01\left(\mathrm{mg} / 100 \mathrm{~g}\right.$ vck) ở $50^{\circ} \mathrm{C}($ Hình 2$)$. Polyphenol và vitamin $\mathrm{C}$ là những hợp chất dễ bị biến đổi ở nhiệt độ cao; trong các nghiên cứu trước đó cũng cho thấy nhiệt độ sấy khoảng $70^{\circ} \mathrm{C}$ làm suy giảm nhiều hàm lượng vitamin $\mathrm{C}$ hơn so với nhiệt độ thấp hơn $70^{\circ} \mathrm{C}$ $[12,13]$. Chỉ số $L^{*}(30,17-30,47)$ và $a^{*}(19,61$ 20,58) của mẫu khác biệt không có ý nghĩa thống kê 
$(p>0,05)$ ở cả ba nhiệt độ sấy. Ở nhiệt độ $70^{\circ} \mathrm{C}$, chỉ số $b^{*}(14,34)$ của mẫu là cao nhất và khác biệt có ý nghĩa thống kê $(p<0,05)$ so với nhiệt độ $50^{\circ} \mathrm{C}(12,47)$, $60{ }^{\circ} \mathrm{C}(11,61)$.

Điểm cảm quan của bánh tráng trái cây ở ba nhiệt độ sấy là khác biệt không có ý nghĩa thống kê $(p>0,05)$ về các chỉ tiêu: màu sắc, mùi vị, kết cấu và tổng thể (Bảng 1). Bánh tráng trái cây sấy ở $60{ }^{\circ} \mathrm{C}$ có điểm số cảm quan cao nhất về màu sắc $(5,75)$ và mùi vị $(5,67)$. Ở nhiệt độ $50^{\circ} \mathrm{C}$ có điểm cảm quan cao nhất về kết cấu $(5,92)$ và tổng thể $(5,83)$. Nhìn chung, sản phẩm được sấy tại ba nhiệt độ khác nhau đều có kết cấu dai mềm; mùi thơm trái cây với mùi đu đủ, chanh dây đặc trưng, vị chua ngọt. Nhiệt độ sấy $60^{\circ} \mathrm{C}$ giúp tiết kiệm thời gian sấy cũng như duy trì tốt hàm lượng các hợp chất chống oxy hóa, chất lượng cảm quản của sản phẩm hơn so với nhiệt độ $50^{\circ} \mathrm{C}$ và $70^{\circ} \mathrm{C}$.

Bảng 1. Ảnh hưởng của nhiệt độ sấy đến chất lượng cảm quan của bánh tráng trái cây

\begin{tabular}{|c|l|l|l|l|}
\hline $\begin{array}{c}\text { Nhiệt độ } \\
\text { sây }\left({ }^{\circ} \mathrm{C}\right)\end{array}$ & $\begin{array}{c}\text { Màu } \\
\text { sắc }\end{array}$ & Mùi vị & $\begin{array}{c}\text { Kết } \\
\text { cấu }\end{array}$ & $\begin{array}{c}\text { Tổng } \\
\text { thể }\end{array}$ \\
\hline 70 & $\begin{array}{l}5,67^{\mathrm{a}} \\
\pm 0,65\end{array}$ & $\begin{array}{l}5,58^{\mathrm{a}} \\
\pm 0,79\end{array}$ & $\begin{array}{l}5,67^{\mathrm{a}} \\
\pm 0,89\end{array}$ & $\begin{array}{l}5,50^{\mathrm{a}} \\
\pm 0,80\end{array}$ \\
\hline 60 & $\begin{array}{l}5,75^{\mathrm{a}} \\
\pm 0,45\end{array}$ & $\begin{array}{l}5,67^{\mathrm{a}} \\
\pm 0,78\end{array}$ & $\begin{array}{l}5,50^{\mathrm{a}} \\
\pm 0,52\end{array}$ & $\begin{array}{l}5,67^{\mathrm{a}} \\
\pm 0,65\end{array}$ \\
\hline 50 & $\begin{array}{l}5,75^{\mathrm{a}} \\
\pm 0,75\end{array}$ & $\begin{array}{l}5,50^{\mathrm{a}} \\
\pm 1,38\end{array}$ & $\begin{array}{l}5,92^{\mathrm{a}} \\
\pm 0,67\end{array}$ & $\begin{array}{l}5,83^{\mathrm{a}} \\
\pm 0,94\end{array}$ \\
\hline
\end{tabular}

1 điểm: cưcc kì không thích và 7 điểm: cưc kì thích. Giá trị trung bình vói các ký tụ $(a, b, c)$ giống nhau trong cùng một cột là khác biệt không có ý nghĩa thống kê ( $p>0.05)$.

\section{2. Ảnh hưởng thời gian sấy đến chất lự̛ng sản phẩm}

Hình 3 cho thấy thời gian sấy càng dài thì độ ẩm và hoạt độ nước của sản phẩm càng giảm. Thời gian sấy tăng, nước trong mẫu càng nhận được nhiều nhiệt lượng, quá trình bay hơi diễn ra càng nhanh. Để hạn chế việc phát triển của vi sinh vật, mâ̂u cần có hoạt độ nước nhỏ hơn 0,6 [14]. Do đó, các mẫu có giá trị hoạt độ nước dao động từ 0,49 đến 0,59 tương ứng với độ ẩm từ 14,89\% đến 19,97\% đã được lựa chọn tiếp tục phân tích hàm lượng các chất chống oxy hóa và chất lượng cảm quan.

Hình 4 cho thấy Hàm lượng vitamin $\mathrm{C}$ ở cả ba mẫu nằm trong khoảng $48,47-50,82 \mathrm{mg} / 100 \mathrm{~g}$ vck, không có sự khác biệt thống kê giữa các giá trị này. Ngược lại, hàm lượng polyphenol có sự khác biệt thống kê, giá trị cao nhất là $346,60(\mathrm{mg} / 100 \mathrm{~g}$ vck) ở mẫu sấy 16,5 giờ và thấp nhất là $294,4(\mathrm{mg} / 100 \mathrm{~g} v \mathrm{vck})$ ở mẫu 13,5 giờ.
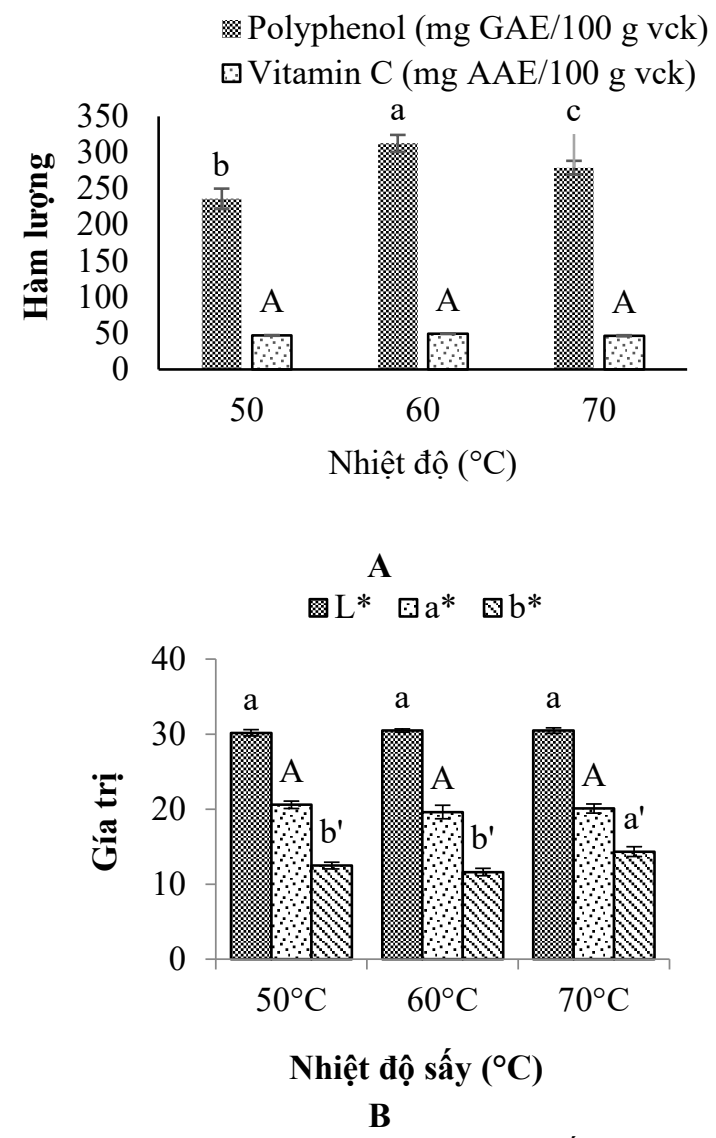

Giá trị trung bình với các ký tụ (a, b, c) giống nhau trong cùng một định dạng cột là khác biệt không có ý nghĩa thống $k \hat{e}(p>0.05) . N=3$.

Hình 2. Ảnh hưởng của nhiệt độ sấy đến (A) một số hợp chất chống oxy hóa và (B) màu sắc của bánh tráng trái cây

Chỉ số $L^{*}(32,09-31,67)$ và $b^{*}(13,88-15,04)$ khác biệt không có ý nghĩa thống kê ( $\mathrm{p}>0.05)$ giữa các mẫu; trong khi đó chỉ số $a^{*}$ lại có sự khác biệt có ý nghĩa thống kê $(p<0.05)$. Chỉ số $a *$ cao nhất là 22,18 ở mẫu sấy 13,5 giờ và thấp nhất là 20,31 ở mẫu sấy 16,5 giờ (Hình 4).

Bảng 2. Ảnh hưởng của thời gian sấy đến chất lượng cảm quan của bánh tráng trái cây

\begin{tabular}{|c|c|c|c|c|}
\hline $\begin{array}{c}\text { Thời } \\
\text { gian } \\
\text { (giờ) }\end{array}$ & $\begin{array}{c}\text { Màu } \\
\text { sắc }\end{array}$ & Mùi vị & $\begin{array}{c}\text { Kết } \\
\text { cấu }\end{array}$ & $\begin{array}{c}\text { Tổng } \\
\text { thể }\end{array}$ \\
\hline 13,5 & $\begin{array}{c}5,45^{\mathrm{a}} \\
\pm 1,21\end{array}$ & $\begin{array}{c}5,91^{\mathrm{a}} \\
\pm 0,54\end{array}$ & $\begin{array}{c}5,55^{\mathrm{a}} \\
\pm 0,82\end{array}$ & $\begin{array}{c}5,91^{\mathrm{a}} \\
\pm 0,70\end{array}$ \\
\hline 15,0 & $\begin{array}{c}5,27^{\mathrm{a}} \\
\pm 1,10\end{array}$ & $\begin{array}{c}5,73^{\mathrm{ab}} \\
\pm 0,79\end{array}$ & $\begin{array}{c}5,27^{\mathrm{a}} \\
\pm 0,65\end{array}$ & $\begin{array}{c}5,36^{\mathrm{ab}} \\
\pm 0,81\end{array}$ \\
\hline 16,5 & $\begin{array}{c}5,36^{\mathrm{a}} \\
\pm 1,21\end{array}$ & $\begin{array}{c}5,18^{\mathrm{b}} \\
\pm 0,75\end{array}$ & $\begin{array}{c}4,82^{\mathrm{a}} \\
\pm 1,33\end{array}$ & $\begin{array}{c}4,73^{\mathrm{b}} \\
\pm 1,10\end{array}$ \\
\hline
\end{tabular}

1 điểm: cưc kì không thích và 7 điểm: cực kì thich. Giá trị trung bình vói các ký tụ $(a, b, c)$ giống nhau trong cùng một cột là khác biệt không có ý nghĩa thống kê (p>0.05). 


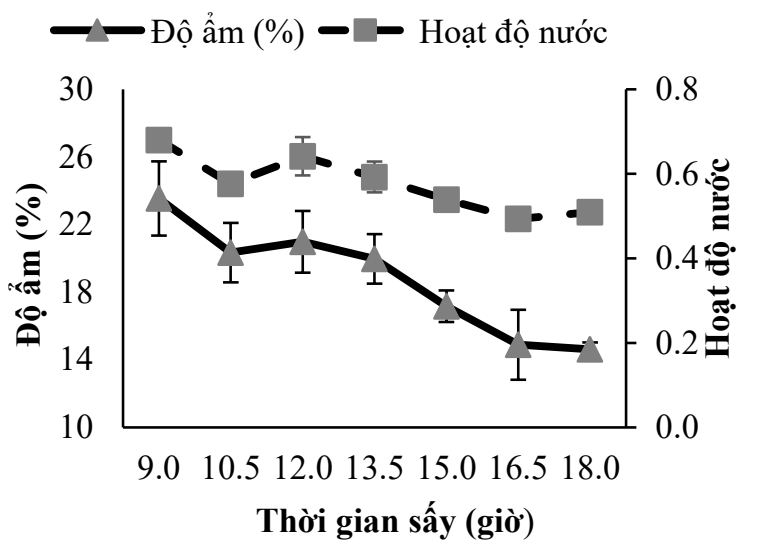

Hình 3. Ảnh hưởng của thời gian sấy ở nhiệt độ $60^{\circ} \mathrm{C}$ đến độ ẩm và hoạt độ nước của bánh tráng trái cây

Thời gian sấy khác nhau đã ảnh hưởng đến đặc điểm cảm quan của sản phẩm. Mẫu sấy trong 13,5 giờ có bề mặt khô hơi dính tay, kết cấu mềm ít dai, khi nhai cảm nhận được mùi hương trái cây; mẫu 15 giờ có bề mặt khô ráo ít dính tay, kết cấu hơi dai, khi nhai cảm nhận được mùi hương trái cây; mẫu 16,5 giờ có bề mặt khô, kết cấu dai cứng, khi nhai ít cảm thấy mùi hương trái cây. Tương ứng với thời gian sấy từ 13,5 giờ đến 16,5 giờ; mẫu có điểm cảm quan màu sắc là 5,36 đến 5,45 ; kết cấu là 4,82 đến 5,55 ; mùi vị là 5,18 đến 5,91 và tổng kết là 4,73 đến 5,91 (Bảng 2 ).

Trong quá trình phân phối, bảo quản và trưng bày, sản phẩm thường phải trải qua một quá trình dài, lúc này sản phẩm có thể bị hồi ẩm dẫn tới làm gia tăng hoạt độ nước ra khỏi vùng an toàn $\left(a_{w}>0,6\right)$, do đó sản phẩm sau sấy cần có giá trị hoạt độ nước nhỏ hơn khác biệt so với giá trị 0,6 . Kết hợp với các kết quả phân tích về hàm lượng các chất chống oxy hóa, chất lượng cảm quan, sản phẩm được sấy trong thời gian 15 giờ cho sản phẩm có chất lượng tốt hơn so với các thời gian sấy còn lại.

\section{Polyphenol (mg GAE/100g vck) \\ vitamin C (mg AAE/100g vck)}

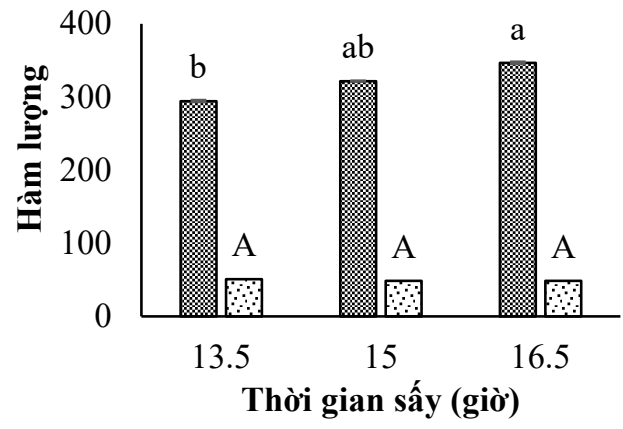

A

\section{3. Ảnh hưởng của loại bao bì bao gói đến chất} lựng sản phẩm trong quá trình bảo quản

Mẫu được bảo quản ở cả hai loại bao bì đều có hàm lượng polyphenol tổng, hàm lượng vitamin $\mathrm{C}$ giảm dần; ngược lại chỉ số $\Delta E$ tăng dần theo thời gian bảo quản.

Sau 60 ngày bảo quản, mẫu có tỷ lệ polyphenol tổng còn lại là $87,23 \%$ (bao $\mathrm{PA}$ ) và $84,42 \%$ (bao $\mathrm{PP}$ tráng nhôm). Trong khi đó, tỷ lệ vitamin $\mathrm{C}$ còn lại và màu sắc của mẫu được bảo quản giữa hai loại bao bì đã có sự khác biệt thống kê $(p<0,05)$. Tỷ lệ vitamin $\mathrm{C}$ còn lại là $83,67 \%$ (bao $\mathrm{PA}$ ) và $78,96 \%$ (bao $\mathrm{PP}$ tráng nhôm) sau 60 ngày bảo quản. Sau 60 ngày bảo quản; chỉ số $\Delta E$ ghi nhận được là 3,41 (bao $\mathrm{PA}$ ) và 2,07 (bao PP tráng nhôm). Trong quá trình bảo quản, oxy có trong khoảng không gian bên trong của bao bì cùng với oxy từ môi trường bảo quản di chuyển vào bên trong bao bì đã tạo điều kiện cho các phản ứng oxy hóa diễn ra [15], ascorbic acid đã bị oxy hóa tạo thành dehydroascorbic acid dẫn đến sự suy giảm của 2,3 diketogluconic và cuối cùng hình thành các hợp chất fufural tham gia vào các phản ứng hóa nâu [5]. Sự suy giảm của hàm lượng vitamin $\mathrm{C}$ trong quá trình bảo quản cũng đã được ghi nhận trong các nghiên cứu trước đó như bánh tráng hỗn hợp đu đủ ổi [16,17], đu đủ táo [12]

Thời gian bảo quản từ 0 đến 60 ngày, giá trị $\Delta E$ của mẫu được bao gói bằng bao $\mathrm{PA}$ tăng từ 2,44 lên 3,41 ; bao tráng nhôm tăng từ 1,26 lên 2,07 . Bao PP tráng nhôm giúp hạn chế sự tiếp xúc của ánh sáng với sản phẩm, cũng như có độ thấm khí, thấm nước thấp hơn so với bao PA; do đó có thể đã giúp giảm các phản ứng oxy hóa, phản ứng hóa nâu của sản phẩm trong quá trình bảo quản. Nghiên cứu về bánh tráng trái mơ cũng cho thấy, sử dụng bao tráng nhôm cho hiệu quả tốt trong duy trì vitamin $\mathrm{C}$ trong quá trình bảo quản [5].

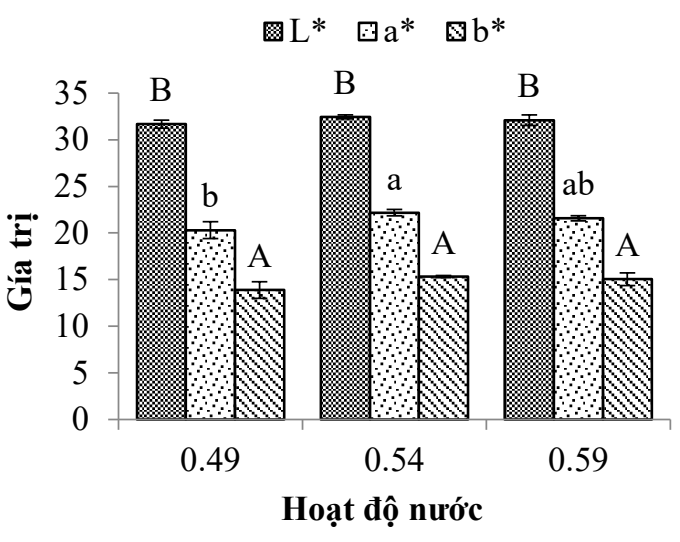

B

Giá trị trung bình với các ký tụ $(a, b, c)$ giống nhau trong cùng một định dạng cột là khác biệt không có ý nghĩa thống kê $(p>0.05) . N=3$.

Hình 4. Ảnh hưởng của thời gian sấy ở nhiệt độ $60^{\circ} \mathrm{C}(\mathrm{A})$ một số hợp chất chống oxy hóa và (B) màu sắc của bánh tráng trái cây 


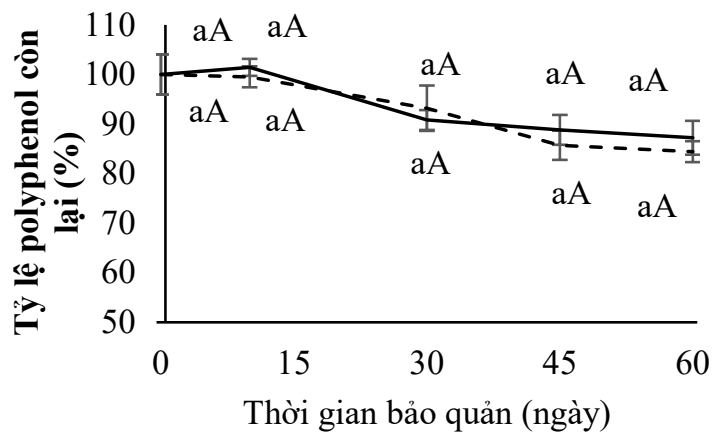

$\mathbf{A}$

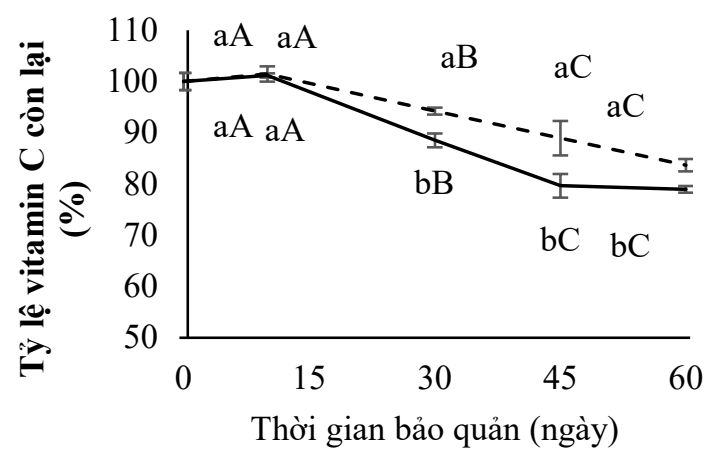

B

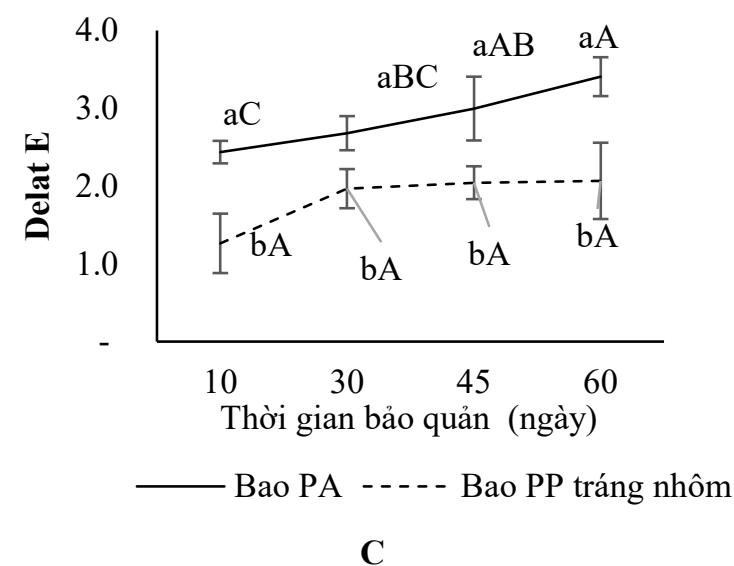

Các giá trị đuợc đánh dấu bằng các ký hiệu khác nhau ( $a, b$, c) thể hiện sự khác biệt có ý nghĩa thống kê giữa các mẫu trong cùng một thời điểm bảo quản. Các giá trị đuoợc đánh dấu bằng các ký hiệu khác nhau $(A, B, C)$ thể hiện sụ khác biệt có ý nghĩa thống kê giữa các thời điểm bảo quản mẫu trong cùng môt loại bao bi. Bao PA: bao polyamide, bao PP tráng nhôm: polypropylen một mặt tráng nhôm.

Hình 5. Ảnh hưởng của loại bao bì bao gói đến (A) tỷ lệ polyphenol tổng còn lại, $(\mathrm{B})$ tỷ lệ vitamin $\mathrm{C}$ còn lại, (C) $\Delta \mathrm{E}$ của bánh tráng trái cây theo thời gian bảo quản tại nhiệt độ phòng.

\section{Kết luận}

Chất lượng của sản phẩm trái cây sấy hỗn hợp dạng bánh tráng chịu tác động của nhiệt độ sấy, thời gian sấy cũng như loại bao bì bao gói. Mẫu được sấy tại nhiệt độ $60{ }^{\circ} \mathrm{C}$ trong 15 giờ có hàm lượng polyphenol là 321,67 mg GAE /100 g vck, hàm lượng vitamin $\mathrm{C}$ là $48,47 \mathrm{mg} \mathrm{AAE} / 100 \mathrm{~g}$ và hoạt độ nước 0,54 , hàm lượng ẩm $17,17 \%$. Sau 2 tháng bảo quản tại nhiệt độ phòng, hàm lượng polyphenol còn lại của mẫu trên $84 \%$ và hàm lượng vitamin $C$ còn lại trên $83 \%$ khi mẫu được bảo quản bằng bao $\mathrm{PA}$ hoặc bao tráng nhôm. Mẫu được bảo quản bằng bao tráng nhôm ít hay đổi màu sắc so với mẫu bảo quản bằng bao $\mathrm{PA}$.

\section{Tài liệu tham khảo}

[1] M. Ghamrawy, 2019. Food loss and waste and value chains, Learning guide. Cairo, FAO. [Online] Available:

http://www.fao.org/3/ca5312en/CA5312EN.pdf

[2] Á. Calín-Sánchez, L. Lipan, M. Cano-Lamadrid, A. Kharaghani, K. Masztalerz, Á. A. CarbonellBarrachina, A. Figiel, Comparison of traditional and novel drying techniques and its effect on quality of fruits, vegetables and aromatic herbs. Foods, vol 9, no 9, September 2020 https://doi.org/10.3390/foods9091261

[3] L. M. Diamante, X. Bai, J. Busch, Fruit leathers: method of preparation and effect of different conditions on qualities, International Journal of Food Science vol 3, pp 1-12, May 2014.

https://doi.org/10.1155/2014/139890

[4] S. Suna, A. Özkan-Karabacak, Investigation of drying kinetics and physicochemical properties of mulberry leather (pestil) dried with different methods, Journal of Food Processing and Preservation, e14051. May 2019.

https://doi.org/10.1111/jfpp.14051

[5] S. K. Sharma, S. P. Chaudhary, V. K. Rao, V. K. Yadav, and Bisht, T. S., Standardization of technology for preparation and storage of wild apricot fruit bar, Journal of Food Science and Technology, vol 50, no 4, pp 784-790, August 2013. https://doi.org/10.1007/s13197-011-0396-y

[6] S. M. Demarchi, N. A. Q. Ruiz, A. Concellón, Giner, S. A., Effect of temperature on hot-air drying rate and on retention of antioxidant capacity in apple leathers, Food and Bioproducts Processing, vol 91, no 4, pp 310-318, October 2013.

https://doi.org/10.1016/j.fbp.2012.11.008

[7] I. Tontul, A. Topuz, Effects of different drying methods on the physicochemical properties of pomegranate leather (pestil), LWT, vol 80, pp 294303, July 2017.

https://doi.org/10.1016/j.lwt.2017.02.035

[8] V.L. Singleton, R. Orthofer, R.M. Lamuela-Raventos, Analysis of total phenols and other oxidation substrates and antioxidants by means of folin-ciocalteu reagent, Methods in Enzymology (edited by J. Abelson, M. Simon), London, UK: Academic Press, 1999, pp. 152-178. https://doi.org/10.1016/S0076-6879(99)99017-1

[9] A. Kapur, A. Hasković, A. Čopra-Janićijević, L. Klepo, A. Topčagić, I. Tahirović, E. Sofić, Spectrophotometric analysis of total ascorbic acid content in various fruits and vegetables, Bulletin of the 
Chemists and Technologists of Bosnia and Herzegovina, vol 38, no 4, pp 39-42, March 2012.

[10] T. C. Kha, M. H. Nguyen, P. D. Roach, C. E. Stathopoulos, 2015, A storage study of encapsulated gac (Momordica cochinchinensis) oil powder and its fortification into foods, Food and Bioproducts Processing vol 96, 113-125, October 2015. https://doi.org/10.1016/j.fbp.2015.07.009

[11] Hà Duyên Tư, Kỹ thuật phân tích cảm quan thực phẩm, Nhà Xuất Bản Khoa Học và Kỹ Thuật, 2010.

[12] C. R. Fulchand, J. V. G. I. M. Pralhad, Studies on effect of drying temperature and storage time on vitamin-C retention capacity and moisture content of papaya-apple fruit leather, Asian Journal of Dairy and Food Research, vol 34, no 4, pp 319-323, December 2015

https://doi.org/10.18805/ajdfr.v34i4.6886

[13] S. Rigi, M. H. Kamani, M. M. S. Atash, Effect of temperature on drying kinetics, antioxidant capacity and vitamin $\mathrm{C}$ content of papaya (Carica papaya Linn.), International Journal of Plant, Animal and Environmental Sciences, vol 4, no 3, pp 413-417,
May 2014.

[14] L. R. Beuchat, Microbial stability as affected by water activity. Cereal Foods World 26, 1981, pp 345-349.

[15] Van B. I., Baetens J. M., Samapundo S., Devlieghere, F., Laleman R., Vandekinderen I., De M. B., Modelling the degradation kinetics of vitamin $\mathrm{C}$ in fruit juice in relation to the initial headspace oxygen concentration, Food Chemistry, vol 134, no 1, pp 207214, September 2012.

https://doi.org/10.1016/j.foodchem.2012.02.096

[16] B. P. Bisen, R. Verma, Standardization of recipes on chemical characteristics and storability of guava and papaya mixed fruit bar, International Journal of Chemical Studies vol 8, no 4, pp 824-829, July 2020. https://doi.org/10.22271/chemi.2020.v8.i4e.9709

[17] L. J. Singh, R. B. Tiwari, K. Ranjitha, Studies on Effect of Different Packaging Materials on Shelf-Life of Blended Guava-Papaya Fruit Leather, European Journal of Nutrition and Food Safety, pp 22-32, August 2020.

https://doi.org/10.9734/ejnfs/2020/v12i830258 